\title{
El humor desde las ciencias sociales. El humor como herramienta de resistencia en movimientos sociales. El caso del 15M.
}

\author{
Ma Isabel Casado Muñoz-Universidad Complutense de Madrid ${ }^{1}$
}

DOI: http://dx.doi.org/10.5565/rev/periferia.513

\begin{abstract}
Resumen
En la actualidad el humor está empezando a expandirse con una gran rapidez en sus aplicaciones, ha entrado en el mundo empresarial y educativo como estrategia para armonizar conflictos y crear sentimiento de grupo, y en el nivel clínico y terapéutico (Martin 2008). Estas aplicaciones recortarían el plano social del humor, al relegarlo a espacios privados o cerrados, lo que contrastaría con la concepción de la risa popular o colectiva en lugares públicos y abiertos, lo cual Bajtin en 1940 ya exponía en su obra sobre el carnaval renacentista. El humor es una emoción pero también un proceso social, estaría presente en protestas sociales no únicamente como herramienta a través de la que transmitir un discurso de forma eficaz, sino que tendría un uso político, actuando en la práctica como un hecho performativo que implicaría una actitud de resistencia política en concordancia con los nuevos movimientos sociales como el 15M.
\end{abstract}

Palabras clave: humor, movimientos sociales, micro-resistencias, empoderamiento ciudadano, emociones.

Abstract. Humour in the Social Sciences. Humour as a tool for resistence in Social Movements. The case of 15-M.

Today, humor is beginning to spread quickly in their applications, it has arrived in business and education worlds as a strategy to harmonize conflicts and create group feeling, and also as a therapy in the clinical level (Martin 2008). These applications would cut the social level of humor, to relegate it to private or closed spaces. This is a contrast with the conception of popular or collective laughter in open public places, that Bakhtin in 1940 exposed in his research about the Renaissance carnival. Humor is not only an emotion, and a cognitive and individual process. Humour is present in social protests as a tool through which it makes an effective speech, but moreover it has a political use as it is a performative fact that implies a resistance and a political attitude consistent with the new social movements such as the movement $15 \mathrm{M}$.

Keywords: humor, social movements, micro-resistences, citizen empowerment, emotions.

1 Enviar correspondencia a: Ma Isabel Casado Muñoz (iscasado11@gmail.com) 
Ma Isabel Casado, El Humor deslde las Ciencias Sociales. El humor como herramienta de resistencia en movimientos sociales. El caso del 15M., perifèria 22(1), junio 2017

revistes.uab.cat/periferia

\section{Introducción}

El análisis del humor ha sido abordado por numerosas disciplinas, tales como la lingüística, el psicoanálisis, la sociología, la psicología, la publicidad, las relaciones internacionales o la medicina, entre otras. La marginalidad del estudio del humor en las ciencias sociales es reseñable si se compara con la gran atención que le ha dedicado la psicología al humor como proceso mental, emocional y evolutivo. Realizar un estudio social del humor permite vislumbrar los alcances del humor como proceso y herramienta social performativa en la acción colectiva, algo que en este artículo aparece concretado a través del movimiento del 15M. El humor lejos de ser algo neutral o meramente comunicacional, lúdico o artístico (aunque también sea todo esto de forma simultánea), puede llegar a ser un margen desde donde enunciar voz o voces políticas disonantes para que sean visibles a la sociedad.

El humor en el $15 \mathrm{M}$ sería un proceso que arroja y recoge información sobre las demandas y aspiraciones del movimiento, un humor que se permite cuestionar la democracia, hasta el momento, pilar tabú, intocable o infranqueable para la opinión pública y la ciudadanía. El humor puede ser usado de forma política, su uso puede aprovechar el margen de subversión que abre el permitido "hablar en broma" y jugar con las libertades de decisión y expresión incompletas de las democracias actuales. El 15M reclamó una renovación política y una reclamación de la voz política de la ciudadanía, usando para ello formas de expresión y acción creativas, las cuales permitieron generar resignificaciones y una democratización de términos o conceptos políticos y de espacios como el de la "Plaza de la Sol-ución"2. El humor se situaría entonces como una herramienta o estrategia que permitiría relacionar ámbitos de la experiencia cotidiana de la ciudadanía con el plano político, politizando sentimientos como la indignación en respuesta a la culpabilización de la

\footnotetext{
2 El nombre de la "Plaza la Sol-ución" hace alusión a un cartel que permanece durante la acampada en una de las salidas del metro de la Puerta del Sol. Se aprovecha el escrito del cartel "Sol" y se le añade el "-ución" y la palabra "plaza" delante. Se reinterpretan las palabras, pero también se reinventan espacios de tránsito como lugares fijos donde hacer política.
} 
Ma Isabel Casado, El Humor deslde las Ciencias Sociales. El humor como herramienta de resistencia en movimientos sociales. El caso del 15M., perifèria 22(1), junio 2017

revistes.uab.cat/periferia

crisis que medios y partidos políticos habían arrojado sobre la ciudadanía de forma individual.

El movimiento social 15M, también conocido como movimiento de Los indignados ${ }^{3}$, Toma la plaza o Spanish revolution, nació tras una multitudinaria manifestación convocada por Democracia Real Ya (DRY) el 15 de mayo de 2011 que recorrió más de cincuenta ciudades de España, una semana de las elecciones autonómicas, el 22 de mayo de $2011^{4}$. En la manifestación participaron colectivos recién creados como Juventud sin futuro o No les votes, así como otros con algo más bagaje como la Plataforma de Afectados por la Hipoteca (PAH) o Anonymous. Desde el año 2008, una fuerte crisis económica afectaba al país, en específico al colectivo de jóvenes, con un $45^{\prime} 1 \%$ de desempleo ${ }^{5}$. La convocatoria fue exitosa y tras ella se procedió a la ocupación de diferentes plazas ${ }^{6}$ y el desarrollo de concentraciones y actividades estratégicas de acción colectiva fundamentadas en el principio de la no-violencia. Este movimiento tuvo una repercusión mediática internacional fuerte y se podría englobar en un ciclo de protestas a nivel global, ya que en esa época aconteció la Primavera Árabe en Túnez y Egipto, y diversas protestas en Islandia, Portugal y Grecia, así como en septiembre del mismo año el movimiento Occupy Wall Street en Nueva York. Las reivindicaciones del 15M se concentraron en la reclamación de un cambio político a través de una participación política activa, se denunció el bipartidismo, el abuso de políticos, banqueros y empresas, el desempleo y la precariedad laboral, y la paulatina pérdida de los derechos a la vivienda, la sanidad, la educación y la cultura. Se desarrollaron asambleas y comisiones en donde se recogieron propuestas y alternativas, y tras las acampadas permanentes en mayo y junio, se creó un sistema de redes de asambleas de barrios que aún sigue presente

\footnotetext{
3 El nombre de los indignados hace un guiño a la obra Indignaos de Stéphane Hessel, publicada en 2010. Este autor es uno de los redactores de la Declaración Universal de los Derechos Humanos de 1948.

4 Estas elecciones autonómicas se celebraron en trece de las diecisiete comunidades autónomas del país, una de ellas, la Comunidad Autónoma de Madrid.

${ }^{5}$ Este dato es proporcionado por el CIS en cuanto al número de jóvenes (menores de 25 años) desempleados en el primer trimestre de 2011 a escala nacional.

${ }^{6}$ La ocupación de las diversas plazas a partir del día 16 de mayo fue respuesta al intento de ocupación de la Puerta del Sol durante la noche del 15 de mayo de 2011 por parte de diversas personas que participaron en la manifestación y el desalojo violento de la policía.
} 
Ma Isabel Casado, El Humor deslde las Ciencias Sociales. El humor como herramienta de resistencia en movimientos sociales. El caso del 15M., perifèria 22(1), junio 2017

revistes.uab.cat/periferia

aunque con mucho menos seguimiento. El movimiento facilitó la creación de un tejido social crítico, el desarrollo de agrupaciones activistas y militantes en el país, así como la renovación de la escena política institucional.

La metodología para la creación de este artículo se basa en mis propias notas de campo, las cuales, a pesar de no ser una etnografía exhaustiva, me permitieron recoger eslóganes y cánticos humorísticos en la Puerta del Sol en Madrid durante el periodo de la acampada entre el 15 de mayo y el 12 de junio, así como la contextualización movimiento. A su vez, la realización de unas prácticas investigación (UCM) sobre la imagen del mismo movimiento en algunos medios tradicionales de comunicación de prensa, me permitieron profundizar en el movimiento, así como extraer otros mensajes humorísticos del análisis de prensa realizado (Ballesteros; Casado; Godoy \& Sánchez 2016) ${ }^{7}$. Los eslóganes de pancartas y cánticos de humor fueron recogidos en una base de datos que cuenta con 60 entradas para facilitar la redacción del artículo8.

El presente ensayo se divide en dos grandes bloques. El primero de ellos es una exploración sobre la teoría del humor, que tiene como objetivo mostrar cómo el humor puede ser usado colectivamente y no es un mero atributo de la personalidad individual, un producto artístico o una forma forma neutral de comunicación. El segundo de los bloques está dedicado al uso del humor en los movimientos sociales ejemplificado en el movimiento 15M. No obstante, el objetivo de ambas partes sería el mismo, evidenciar cómo emociones y procesos cognitivos como el humor han sido individualizados en nuestra sociedad occidental, haciendo más complicado el reconocimiento de las emociones colectivas enmarcados en lógicas socioestructurales más amplias.

\footnotetext{
7 La investigación realizada colectivamente se basó en un análisis de prensa de los periódicos "La Razón", "Público" y "El País" entre el 15 de mayo de 2011 y el 12 de junio de 2011, periodo de la acampada en la Puerta del Sol en Madrid. Se analizaron para ello 379 artículos.

8 Otro elemento que permitió el desarrollo de este trabajo fue la elaboración de pequeño trabajo etnográfico sobre los monólogos de humor sobre la escena artística madrileña durante mis estudios que me permitió la lectura de una bibliografía diversa sobre las teorías del humor.
} 
Ma Isabel Casado, El Humor deslde las Ciencias Sociales. El humor como herramienta de resistencia en movimientos sociales. El caso del 15M., perifèria 22(1), junio 2017

revistes.uab.cat/periferia

\section{Emociones, Sociedad y Cultura. Nociones sobre el humor}

\section{El humor como proceso social}

El estudio de las emociones no ha sido apenas desarrollado en las investigaciones sociales hasta hace unas dos décadas (Hart 2007; Romanos 2013) por creerse hasta hace poco tiempo campo exclusivo de la psicología que le ha dado un enfoque más cognitivo e individual (Apte 1985), y que en la actualidad lo trata como método o psicoterapia (risoterapia), olvidando el lado socio-estructural del mismo. Algunos autores como Eva Illouz han expuesto cómo la psicología ha intentado controlar las emociones o gestionarlas psicoterapéuticamente de forma individual (Illouz 2007). Históricamente, según como Ramírez Goicoechea dice, esto derivaría en parte de "la tradición filosófica occidental, heredera del judeocristianismo y el cartesianismo que relega lo emocional a lo visceral y lo pasional, instintos 'bajos ligados a lo corporal frente a lo mental' " (Ramírez Goicoechea 2001:183). Le Breton, uno de los más conocidos exponentes de la antropología de las emociones, ha dicho en relación con la forma clásica en la que se han entendido las emociones en occidente que: "La emoción es naturalizada y se ve como una forma puramente biológica, se busca las expresiones faciales que le corresponden, como si se tratara de un recurso finito y sin ambigüedades, desprendido del actor social" (Le Breton 2012:72).

El humor sería por tanto, además de una respuesta emocional y psíquica, un proceso también social como subraya el sociólogo Eduardo Romanos (2013) al hablar del humor en los movimientos sociales. El humor sería un aspecto muy importante para entender el pensamiento y los aspectos más profundos de una cultura: "El humor refleja las percepciones culturales más profundas, ofreciéndonos así un poderoso instrumento para entender las formas de pensar y sentir que la cultura ha modelado" (Henk Driessen 1999:227). Aunque la risa y la expresión emocional de la comicidad serían universales y propios del ser humano (Jauregui 2008; Apte 1985; Berger 1999), algo que ya Bergson enunció en su obra La risa a principios del XX, no lo sería su expresión sociocultural, la definición de qué es o no es cómico, así como las costumbres o las instituciones de la misma (Jauregui 
Ma Isabel Casado, El Humor deslde las Ciencias Sociales. El humor como herramienta de resistencia en movimientos sociales. El caso del 15M., perifèria 22(1), junio 2017

revistes.uab.cat/periferia

2008). El humor dependería de los agentes que lo usan, así como de quienes lo interpretan y del contexto específico donde se produce e interpreta.

\section{La dualidad serio/humor, la deslegitimación histórica del humor}

Sería importante no caer en la dualidad de "serio/humor", ya que aunque el humor pueda relacionarse en un primer momento con lo jocoso, el hecho de que se esté usando, así como lo que está diciendo, puede estar comunicando consciente o inconscientemente cosas "serias" (Abril 1991; Berger 1999), algo que Mary Douglas enfatiza al expresar cómo el grado de mordacidad de un chiste no sería sinónimo de su capacidad para provocar la risa (Douglas 1978). La dualidad serio/humor sería una construcción histórica, así como lo es pensar que el "estado normal" sería el estar serio o sereno y el alterado, aquel en el que se hace uso del humor. "Son abrumadoras las evidencias etnográficas que desmienten el prejuicio positivista según el cual, la seriedad equivale a un grado cero o un estado de "normalidad" del lenguaje, frente al que la broma, el sarcasmo o la agudeza constituirían estados de excepción discursiva" (Abril 1991:60).

Eludir el análisis del humor por considerarlo un arte, un juego o un formato expresivo neutral, sería reproducir una deslegitimación histórico-social de la que ha sido objeto, así como invisibilizar su uso por parte de agentes e instituciones. Infante Yupanqui expone la axiología del desequilibrio moral, que explica cómo desde la psiquiatría "el humor se asoció a patología, a un desequilibrio temperamental puesto en práctica por un individuo colérico, impulsivo, flemático, cuya sangre o bilis no lograba ser contenida" (Infante Yupanqui 2008:250). El formato de expresión del humor es un muchos casos la oralidad, algo que le habría restado importancia al ser considerado un formato de expresión con menos autoridad a la hora de producir saber o un conocimiento culto (Driessen 1999).

\section{Diferencias teóricas sobre el humor entre la psicología y las ciencias sociales}

Infante Yupanqui explica cómo el humor no puede ser estudiado únicamente de forma unidimensional, ya sea por el plano simbólico, por el estético, por el social, el 
Ma Isabel Casado, El Humor deslde las Ciencias Sociales. El humor como herramienta de resistencia en movimientos sociales. El caso del 15M., perifèria 22(1), junio 2017

revistes.uab.cat/periferia

cultural, o el psicológico, aunque explicita que todas las disciplinas han buscado un exclusivismo a la hora de explicarlo (Infante Yupanqui 2008:248). He decidido desarrollar un apartado específico donde explicar el bagaje teórico que se le ha dado desde la psicología como disciplina que más ha monopolizado estos estudios, es decir, la perspectiva hegemónica, y otro apartado para exponer los aportes desde las ciencias sociales, los cuales se han esforzado por mostrar los componentes culturales, sociales y políticos.

\section{La teoría del humor en la psicología}

Desde la psicología se han dado cuatro grandes teorías que explican el humor, a las cuales el psicólogo Rod Martin (2008) ha hecho referencia:

1) Teoría psicoanalítica.- Freud en 1905 con "El chiste en relación con el inconsciente" expone que la risa produce placer al descargar tensión nerviosa excesiva al ser una forma de liberarse de los límites de los tabúes sociales impuestos por la cultura. Para Eva Illouz lo que Freud conseguiría con su aportación teórica es la traducción de sentimientos en síntomas, lo cual psicoanalizaría las emociones, dando una visión muy negativa de las emociones como signos de trastornos mentales (Illouz 2007).

2) Teoría de la superioridad o menosprecio.- Esta enfatizaría en el uso del humor para agredir y demostrar superioridad y poder, una forma de exclusión basada en la separación entre "nosotros" y "ellos", una defensa ante "los otros", como expresa el psicólogo Ziv Avner; el humor podría usarse también como un arma, una forma de menosprecio, ridiculización y humillación (Berger 1997). Esta teoría de la superioridad relaciona directamente el humor con la identidad grupal, algo útil sobretodo a la hora de entender el uso del humor como defensa del "nosotros" en los movimientos sociales.

3) Teoría de la incongruencia.- Esta teoría cognitiva se basa en que el humor se explica como producto de una situación de disociación, es decir, cuando algo se percibe desde dos marcos de referencia consistentes pero incompatibles entre sí. Para Arthur Koestler (1964), un humorista elige deliberadamente códigos 
Ma Isabel Casado, El Humor deslde las Ciencias Sociales. El humor como herramienta de resistencia en movimientos sociales. El caso del 15M., perifèria 22(1), junio 2017

revistes.uab.cat/periferia

discordantes en el comportamiento y el discurso expresando las incongruencias o paradojas. Esta teoría se ha utilizado desde la antropología lingüística (Lakoff y Johnson 1995) y la sociología de los movimientos sociales (Tejerina 1998) para explicar los cambios de marcos de pensamiento, sobre todo relacionándolos con la metáfora como productora/creadora de realidad social.

4) Teoría de la inversión.- Correspondería a una visión del humor como una actividad lúdica, creadora de un mundo interno o privado que protege y da seguridad psicológica a las personas al servir para aislarse de lo cotidiano. Considera al humor como una válvula de escape, refugio individual y vuelve a caer en la lógica sintomática de la teoría psicoanalítica. Sin embargo, Bajtin (2003) realizó una visión político social de la teoría de la inversión que expresó cómo el humor puede servir para enfrentar y subvertir simbólicamente el mundo social a través del carnaval y la inversión ritual.

En nuestra sociedad el humor se utiliza en terapias como la risoterapia para modificar las actitudes ante los conflictos personales o grupales, o se introduce en el seno de empresas y grupos de trabajo para relajar el ambiente, mejorar la comunicación y resolver conflictos. Esta sería una visión armoniosa del humor que recortaría su potencial social a un uso terapéutico que puede relacionarse con la psicología humanista o la autoayuda. Sin embargo, el humor no sólo sirve para relajar y armonizar tensiones, sino que sería usado como forma de problematizar y manifestar el conflicto.

\section{La teoría social del humor}

"Se ha dicho que la sociología y el humor tienen bastante en común, que comparten el mismo propósito de relativizar las rutinas más asentadas de la vida cotidiana sometiéndolas a un examen minucioso" (Henk Driessen 1999: 232).

En general, la antropología no ha dedicado mucho espacio en sus análisis al humor, aunque posiblemente el uso de la risa y el humor en sus manifestaciones sociales sea algo que frecuentemente se anote en las observaciones que los antropólogos 
Ma Isabel Casado, El Humor deslde las Ciencias Sociales. El humor como herramienta de resistencia en movimientos sociales. El caso del 15M., perifèria 22(1), junio 2017

revistes.uab.cat/periferia

hacen en sus trabajos de campo (Henk Driessen 2008:238). Por ello, he decidido incluir trabajos de otras disciplinas sociales para suplir esta ausencia de bagaje teórico. Aunque la psicología ha sido la disciplina hegemónica, con el desarrollo de la sociología de las emociones y de la antropología cultural, han nacido estudios sobre el uso de la creatividad, el arte y el humor en protestas y movimientos sociales (Romanos 2013). He introducido tres líneas teóricas principales de desarrollo teórico social del humor: 1) la variabilidad cultural; 2) el posmodernismo; y 3 ) las teorías sobre el uso y la práctica.

1) Análisis sobre la variabilidad sociocultural del humor.- Existen muchas variables sociales y culturales en relación con la risa que han sido estudiadas por distintos investigadores, tales como: la edad y el sexo (Apte 1985), el lugar y el tiempo histórico (Reche 2008), la fase económica y de desarrollo (Driessen 1999), la etnicidad y la religión (Apte 1995), la distancia con el poder, el género o el tipo de sociedad (Paéz y Mendiburo 2011). El estudio de esas variables nos ayudaron a ver las diferencias entre la percepción y la producción del humor como factor cultural; sin embargo, no profundizarían en la perspectiva de relaciones de fuerzas y de poder.

2) El humor para la teoría social posmoderna.- Las tesis posmodernas enfatizan el uso del humor como elemento clave y en aumento en la identidad y relaciones posmodernas, en respuesta a la pérdida de fe en la razón moderna. Lipovetsky (1986) es el mayor representante de estas reflexiones, expone que el humor siempre ha existido pero que no es hasta la posmodernidad cuando las sociedades lo colocan en primera fila, caracterizándose como hedonista, lúdico y autoreflexivo debido a la crítica de certezas absolutas.

3) Análisis del humor como una forma de acción.- Este apartado analiza las teorías que exponen el componente performativo del humor, es decir, sus usos sociales, así como el análisis estructural de relaciones de fuerza. He diferenciando dos líneas analíticas, que lejos de ser excluyentes, son complementarias.

Estarían por un lado los análisis que tratan el humor como forma de resistencia política. Uno de los libros más importantes del siglo XX sobre el humor fue el de La 
Ma Isabel Casado, El Humor deslde las Ciencias Sociales. El humor como herramienta de resistencia en movimientos sociales. El caso del 15M., perifèria 22(1), junio 2017

revistes.uab.cat/periferia

Risa de Bergson (2004), este considera la risa como algo puramente humano y colectivo, e intelectual. Pero entender la risa sólo intelectualmente, invisibilizaría que el humor puede también servir para catalizar y expresar emociones colectivas como la ira, el descontento o la esperanza, algo que indirectamente Bajtin expondrá años más tarde. En 1940, Bajtin con su obra La cultura popular en la edad media $y$ en el renacimiento, hace una interpretación que revolucionó los estudios teóricos sobre el humor, la risa y la fiesta. Este entiende el humor como una renovación de ideas y prácticas, una subversión a los discursos hegemónicos por parte del sentir popular y una forma inconsciente de manifestar un cambio de mentalidad o una necesidad del mismo a través de medios simbólicos como el carnaval y la risa. Para Bajtin: "La risa y la cosmovisión carnavalescas, destruyen la seriedad unilateral y las pretensiones de significación incondicional e intemporal y liberan a la vez la conciencia, el pensamiento y la imaginación humanas, que quedan así disponibles para el desarrollo de nuevas posibilidades" (Bajtin 2003:44). Para Berger, el humor es entendido como una emoción que refuerza la identidad grupal, que habría sido históricamente reducido y contenido en obras artísticas como el teatro por ser más aceptables y controlables.

Por otro lado se encontrarían los análisis que tratan el humor como forma de control o reproducción social. Para Rod Martin (2008), una de las funciones del humor sería actuar como forma de control o comunicación de reglas implícitas y reforzar estatus y jerarquía. Mary Douglas (1978) explica cómo el humor ha sido censurado para controlar, paliando así la capacidad de improvisación y la capacidad de rebelarse de la población. Sergio López en el artículo "Humor y poder. Una afinidad comunicativa en el proceso social" (2008) estudió las formas de humor en una empresa y su relación con el poder y el capital cultural, centrándose en el uso del humor de la figura del jefe y su posición de legitimidad para bromear.

El humor, por tanto, además de servir como resistencia y forma de dotar de identidad grupal, también se ha censurado interesadamente desde la institución para impedir precisamente que logre esta "función" subversiva, así como se ha utilizado para reproducir desigualdades engendradas en el seno de la estructura 
Ma Isabel Casado, El Humor deslde las Ciencias Sociales. El humor como herramienta de resistencia en movimientos sociales. El caso del 15M., perifèria 22(1), junio 2017

revistes.uab.cat/periferia

social. Es por tanto, un proceso social complejo que no puede reducirse a una única función o uso social.

\section{Humor, poder y protesta}

\section{Cambio de marcos de pensamiento y resistencia política}

Existen metáforas que actúan en nuestro imaginario social y estas son utilizadas socialmente en nuestros sistemas de pensamiento y discursos, pero también se pueden crear nuevas metáforas que nos proporcionarían una "nueva comprensión de nuestra experiencia" y "activan nuevas percepciones y acciones" (Lakoff y Johnson 1995), es decir, alterarían nuestros marcos de significado. $Y$ es precisamente esta potencialidad metafórica del humor puesta en práctica, lo que permitiría en una gran medida a los movimientos sociales un código desde el que poder analizar la situación social con distancia y a la vez la posibilidad de ser escuchados. Sería lo que Scott denomina como una forma de resistencia no evidente que permitiría crear sistemas o marcos de significado alternativos a los de los discursos hegemónicos, posibilitando el resignificar y subvertir conceptos e imágenes (Scott 2003). La creatividad y el humor se convertirían en formas usadas por parte de los grupos con menos poder de enunciar sus críticas, ya que " es una forma aceptable/permisible de contestación al entorno" (Vivero García 2011: 207).

\section{El aumento del humor en los nuevos movimientos sociales}

El uso del humor en los movimientos sociales ha aumentado en las últimas décadas. La conexión entre humor y protesta organizada no es algo novedoso, en 1983 Hiller la identifica en su "Humor and Hostility: A Neglected Aspect of Social Movement Analysis", donde estudia el caso del uso del humor en el movimiento separatista del Oeste de Canadá a través de un enclave teórico basado en el interaccionismo simbólico (Hiller 1983). Según Bruner (2005), el humor se ha hecho visible en los recientes ciclos de protesta como los "movimientos prodemocracia" en Europa (Romanos 2013). Este aumento del humor se debe a lo que Tucker (2010) Ilamaría una "estetización de los movimientos sociales" como proceso en el que se expone una visión alternativa de la sociedad, de las 
Ma Isabel Casado, El Humor deslde las Ciencias Sociales. El humor como herramienta de resistencia en movimientos sociales. El caso del 15M., perifèria 22(1), junio 2017

revistes.uab.cat/periferia

identidades y de las experiencias, una dimensión transgresora de la estética más acentuada ante los cambios del neoliberalismo y la globalización (Romanos 2013). Estos nuevos movimientos estarían caracterizados ya no sólo por su discurso, sino por la innovación y la imaginación en donde la risa juega un rol importante a través de recursos tales como la resignificacion de símbolos y productos culturales (Romanos 2013).

\section{Humor político y 15M}

"Esto es esperanza y no la presidenta"9

(Cántico de la acampada coreado enfrente de la Presidencia de la Comunidad de Madrid en la Puerta del Sol)

El 15M, a través del humor como estrategia simbólica, entre otros mecanismos, resignificó al "burlarse de la democracia", con eslóganes como "me gustas democracia porque estás como ausente", la propia noción de democracia, es decir, la interpretación del propio sistema político. El significante se renovó de significado social, lo que posibilitaría una mayor rapidez en el cambio de marcos de pensamiento político. Lo que para Bajtin suponía el carnaval medieval, tuvo una gran similitud con la acampada de Sol durante mayo de 2011 y muchas de las estrategias de los nuevos movimientos sociales basadas en la creatividad, el arte, el humor, la fiesta o la batukada. Ambas realidades supondrían una superación simbólica del miedo al relativizarlo a través de emociones, argumentos renovados (patrimonio del pueblo) y formas rituales de expresión en oposición a la rigidez de la clase política. El uso del "no tenemos miedo" por parte del movimiento 15M estaría en total consonancia con el carnaval renacentista que retrata Bajtin, revelando una lucha por el cambio de mentalidad y una superación simbólica de la autoridad.

Dentro de las ciencias sociales, existen tres trabajos que han tratado la conexión entre humor y $15 \mathrm{M}$ de forma directa, son los realizados por el ya citado sociólogo

9 Este cántico hace alusión a la entonces presidenta de la Comunidad Autónoma de Madrid Esperanza Aguirre, política del Partido Popular que estuvo en la presidencia autonómica del año 2003 al año 2012. 
Ma Isabel Casado, El Humor deslde las Ciencias Sociales. El humor como herramienta de resistencia en movimientos sociales. El caso del 15M., perifèria 22(1), junio 2017

revistes.uab.cat/periferia

Eduardo Romanos (2013), el antropólogo Antón Fernández de Rota (2013) y la lingüista María Dolores Vivero (2011). El trabajo de Eduardo Romanos es un recorrido por diversos eslóganes y acciones cómicas de la acampada del 15M que reconocen que el humor es actuado de forma estratégica por el movimiento. Vivero realizó una revisión de eslóganes en el 15M aplicando el análisis crítico del discurso y la teoría marxista para remarcar el componente subversivo de esos mensajes. Sin embargo, la aportación más reseñable en términos antropológicos viene de la mano de Antón Fernández, el cual expuso cómo en el 15M se dan unas "estéticas de la indignación" que contribuyen a definir una estrategia de hiperidentificación democrática, que ha sabido sacar partido al humor paródico y que hizo posible el crecimiento del movimiento y combatió su fácil clasificación o encasillamiento.

Berger, en su obra La risa redentora (1999) distinguió el humor como crítica/sátira del humor como consuelo y del humor como juego intelectual, sin embargo; ¿sería lícito separar estos tipos de humor? Bajo el prisma del humor en el 15M podríamos decir que esta distinción analítica no tiene sentido, sería un humor poliédrico ya que eslóganes humorísticos e ingeniosos que se escucharon en la plaza actuaron tanto en el reconocimiento de ciertas desgracias individuales como compartidas (como una especie de consuelo), así como una forma de reivindicar que la situación social era potencialmente injusta, es decir como crítica. "Tengo una carrera y como mortadela", "No tenemos casa, nos quedamos en la plaza" o "Nuestros sueños no caben en sus urnas" serían tanto una forma de consuelo social, como una forma de crítica y sátira social.

\section{Las metáforas incorporadas y encarnadas del 15M}

"Así, así, así vota Madrid" (Grito en la Plaza de Sol que da comienzo a la jornada de reflexión, día 21M)

El uso de la metáfora en el $15 \mathrm{M}$ no se realizó únicamente a través del humor como recurso o herramienta de acción y de vivencia, sino que el movimiento utilizó otros 
Ma Isabel Casado, El Humor deslde las Ciencias Sociales. El humor como herramienta de resistencia en movimientos sociales. El caso del 15M., perifèria 22(1), junio 2017

revistes.uab.cat/periferia

recursos aparentemente artísticos como el teatro y la pintura, o de acción directa como la creación de espacios como: las asambleas como forma de política corporeizada, una biblioteca como lugar transmisor de conocimientos, un archivo documental y gráfico compuesto colectivamente, o la decisión de crear información propia independiente de los medios, entre otros, como metáforas de que otra realidad política es posible. La creación de las metáforas como estrategia, es algo que Tejerina (1998), experto en la construcción de identidad en los movimientos sociales, ha considerado fundamental para la creación de un sentido común alternativo.

Las propias identidades tuvieron un componente metafórico que permitió dar laxitud al movimiento en su propio discurso y cobertura, tal es el caso de uno de los nombres que adoptó el 15M, el del movimiento de "los indignados", el cual permite sumar en la lucha a todos los sectores y personas de la sociedad que considerasen en peligro su dignidad como personas. Estas nuevas metáforas y usos metafóricos de los significados son actuados, puestos en práctica y experimentados por las personas que componen el movimiento en el espacio de la acampada, lo cual habría alejado la metáfora de su función comunicacional, explicitando su uso en una creatividad inclusiva y práctica, generadora de nuevos conceptos y significados vivenciales, es decir, bajando el concepto abstracto de democracia a la ejemplificación en la propia acampada y la encarnación de los discursos (Diz Reboredo 2013).

\section{El humor en el $15 \mathrm{M}$, un humor colectivo y público, un patrimonio popular}

"Si no nos dejáis soñar, no os dejaremos dormir" Mensaje escrito en varias pancartas de la acampada

No se puede reducir el humor que se dio en el $15 \mathrm{M}$ solo en el sentido de un fin 
Ma Isabel Casado, El Humor deslde las Ciencias Sociales. El humor como herramienta de resistencia en movimientos sociales. El caso del 15M., perifèria 22(1), junio 2017

revistes.uab.cat/periferia

social, ya que podríamos caer en la tentativa atractiva de los análisis causales y esto invisibilizaría que se usara tanto internamente para producir identidad grupal y una relajación de las posibles disputas internas del movimiento, como a nivel externo actuando como crítica social y forma de captar la atención por parte de medios y de las personas ajenas al movimiento/ciudadanía global (Romanos 2013). En las siguientes páginas se expondrá cómo este humor del movimiento además de haber sido una forma de acción estratégica con el fin de dotar de identidad al 15M y de ser un elemento para dar más eficacia comunicativa al movimiento, podría considerarse además una manifestación de un capital cultural y una expresión de violencia simbólica de resistencia "no violenta" muy en concordancia con el propio discurso del movimiento. El humor en el 15M no estuvo cerrado a un público ni se da en un espacio privado, aparte de que este no fue el producto de individuos particulares con nombre y apellidos (cómicos), sino un humor colectivo y compartido. El humor en el $15 \mathrm{M}$ se dio en las plazas, un lugar público y abierto para todos los ciudadanos. Los eslóganes y pancartas humorísticos se movieron además a través de redes sociales, se subieron imágenes de ellos o se twitearon y retwitearon, además de que los medios de comunicación dieron difusión a algunos de ellos, es decir, se volvieron expansivos y más públicos, dejaron por tanto de tener una autoría inicial, para reutilizarse colectivamente. No habrían sido mensajes pensados en el lenguaje escrito formal, sino en el de la oralidad y en la posibilidad de memorización, que es algo que Infante Yupanqui resalta del uso colectivo del humor como algo importante para que los cambios discursivoideológicos perduren y se legitimen a medio plazo.

El humor como herramienta pública podría haber servido al 15M para sintetizar información, coordinarla analíticamente de forma sencilla y hacer así denuncias públicas en un formato de reflexión memorizable. Que se olvidase la autoría inicial, se anonimizara y se colectivizase el mensaje como "patrimonio colectivo" o popular del movimiento, así como que se aprovechara (no digo que consciente en su totalidad) el margen de que el humor es considerado socialmente como 
Ma Isabel Casado, El Humor deslde las Ciencias Sociales. El humor como herramienta de resistencia en movimientos sociales. El caso del 15M., perifèria 22(1), junio 2017

revistes.uab.cat/periferia

herramienta de comunicación neutral/ artística, son elementos que favorecerían al movimiento en la representación de una resistencia pacífica, y de unos recursos o patrimonio colectivos, necesarios para enunciar su legitimidad. El humor en el 15M como herramienta no habría sido una forma premeditada de acción estratégica en el sentido literal, la palabra herramienta no habría nacido de una decisión pautada y normada, sino que apareció en el devenir del proceso reivindicativo con la espontaneidad con la que se desarrolla el mismo, algo que Antón Fernández ha desarrollado a través de una revisión del término de Gilles Deleuze de acontecimiento (Antón Fernández 2013).

\section{EI 15M como acontecimiento $y$ el humor como acción rupturista $y$ catalizador de emociones}

"Papá, ¿me lees un cuento? ¿Qué tal el de que aún tenemos libertad de expresión?"

(Cartel de la acampada que se muestra a modo de cómic).

Antón Fernández atiende a las nociones de Deleuze sobre el término "acontecimiento" para explicar el carácter innovador y rupturista del 15M. Este explica cómo "desde la filosofía de la innovación aquello que se prepara en un lugar pautado, en determinadas circunstancias conocidas y protocolarias, sobre todo desde arriba con el fin de ofrecer una noticia a los media, nunca podrá ser definido como acontecimiento" (Fernández de Rota 2013:2), por tanto, para Antón Fernández, las convocatorias de "No les votes", "Democracia Real Ya", etc, no habrían sido un acontecimiento, sino que el 15M no aconteció hasta que se acampó en Sol, ya que fue algo no pautado y espontáneo, algo que acontece, y de ahí su potencialidad. El autor lo ha definido como la aparición de un sujeto social: "Tener un cuerpo no es un dato a priori sino un deber moral, que diría Leibniz, o político en nuestro caso" (Antón Fernández 2013:3), el cuerpo como algo político más allá de ser un cuerpo físico o social, un cuerpo político que aparece como una biolegitimidad reformulada y empoderada a través de un discurso que exigió que la ciudadanía entrase de forma más participativa en la democracia, es decir, que 
Ma Isabel Casado, El Humor deslde las Ciencias Sociales. El humor como herramienta de resistencia en movimientos sociales. El caso del 15M., perifèria 22(1), junio 2017

revistes.uab.cat/periferia

tuviera más presencia política y poder político.

En épocas de crisis, el humor tiende a aparecer mucho más como forma de reivindicación, evasión y consuelo (Henk Driessen 1999). En la historia de España, destaca la censura sufrida en la dictadura franquista, la cual limitó y controló el humor político durante esos años (Ferrer y Roca 1977). Las críticas humorísticas durante los primeros años de censura, tal y como relatan Ferrer y Roca, se limitaron al carácter municipal y a la subida de precios, algo que claramente contrasta con el carácter global de las críticas del 15M. En los años sesenta se produjo un cambio en el humor político de España por la ley de prensa e imprenta, aumentando el humor gráfico y su agudeza a través de publicaciones primero como La Codorniz y en la década de los setenta como El Hombre Lobo, El Papus y Por favor. Por otro lado, la transición poco rupturista, haría que el propio humor no fuese tampoco rupturista en términos políticos hasta finales del XX y comienzos del siglo XXI.

En el 15M, medios de comunicación alternativos y redes sociales utilizaron este humor de forma extensiva, haciendo posible hacer críticas políticas que incluyeron en el debate público temas que hasta el momento eran intocables, así como normalizando posturas políticas de crítica social antes consideradas "antisistemas". En opinión de Romanos, el 15M supondría una ruptura con las típicas protestas al facilitar la participación de la gente que no tiene una experiencia activista en el movimiento, y el humor habría sido una forma de ruptura de esquemas mentales, una estrategia de renovación discursivo-ideológica, una forma de dotar de identidad al movimiento y de reconocimiento, así como una forma de mostrar cómo existirían maneras creativas de problematizar la política.

El 15M, a través de emociones como la indignación política, enunció una serie de reivindicaciones ciudadanas, reunió voces disonantes que luchaban por tener existencia política a través de discursos basados en la creatividad y el humor, ambos como catalizadores de emociones que dieron legitimidad y efectividad simbólica al movimiento. Tanto Romanos como Vivero han expuesto en sus artículos cómo las nuevas formas de movilización como el 15M han sido cada vez 
Ma Isabel Casado, El Humor deslde las Ciencias Sociales. El humor como herramienta de resistencia en movimientos sociales. El caso del 15M., perifèria 22(1), junio 2017

revistes.uab.cat/periferia

más contrarias al espíritu de seriedad del militarismo/activismo tradicional. Para Vivero, el humor ayuda a transformar, al menos la manera de concebir el mundo, transgrediendo los códigos socio-discursivos y, en particular, las representaciones y mentalidades socialmente dominantes. El activismo de 15M fue un activismo apenas institucionalizado que potenció la creatividad individual y la espontaneidad del movimiento, es decir, que permitió expresar la multiplicidad de voces políticas de las personas.

La problematización de las reclamaciones políticas a través de la creatividad habrían sido una forma de expresar que, aunque no se les permitiese una voz política democrática, los ciudadanos estaban capacitados para pensar de forma democrática y crítica; que la juventud, entre otros sectores, no eran ni ninis, ni borregos apolitizados como se les había venido considerando, como bien expresan estos eslóganes que se escucharon en la acampada Sol durante su transcurso en varias ocasiones: "Somos ninis, ni PSOE, ni PP", y "No somos apolíticos, estamos haciendo política".

\section{Humor en el 15M y violencia simbólica}

"Desabrochen el cerebro tan a menudo como sus braguetas" (Pancarta colocada en la cúpula de la Renfe Sol durante la acampada)

La teoría bourdiana define la formación social como un sistema de relaciones de fuerza y de sentido entre grupos y clases, es decir, un ejercicio de la violencia simbólica en todos los espacios, por tanto, el humor también tiene un "componente violento" como muestran ciertas teorías anteriormente expuestas como la psicológica de la superioridad o sus versiones sociales más completas como la de la reproducción de desigualdades. Estas últimas, muestran al humor en muchas ocasiones como una exhibición de capital cultural o una forma de superioridad. A pesar de que el humor del 15M puede utilizase los márgenes de "lo no serio" y de "lo inofensivo", esto no significa que este humor no tuviera un componente de violencia simbólica en busca de una efectividad social. Querer eludir la noción de 
Ma Isabel Casado, El Humor deslde las Ciencias Sociales. El humor como herramienta de resistencia en movimientos sociales. El caso del 15M., perifèria 22(1), junio 2017

revistes.uab.cat/periferia

violencia del 15M analíticamente, aunque esta fuese simbólica, por ir en contra de su discurso interno sobre la "no violencia", podría invisibilizar el abanico de juego de fuerzas y las formas que estas diferentes fuerzas tomaron. La crítica social y la subversión de los límites de la capacidad relacional de los discursos políticos hegemónicos, haría que el humor fuese un mecanismo para el cambio social a medio/largo plazo. El 15M buscó responsabilidades y las enunció de diversas formas, ya sea a través de asambleas y manifiestos, pero también a través de mensajes cómicos que evidenciaron la desigualdad social y la legitimidad de la indignación/frustración: "Queremos un pisito como el del principito", "Fíate de un banco y dormirás en él", o "Alquilo mi alma por una hipoteca".

Partiendo de los Estudios Críticos del Discurso, Sierra Infante (2011), estudió cómo se contestaría desde el $15 \mathrm{M}$ a los abusos de poder como la manipulación o la censura a través de una crítica social enunciada a través del humor. Esta autora ha expuesto que esta burla en el $15 \mathrm{M}$ tuvo un componente subversivo contrahegemónico al burlarse de líderes democráticos, los cuales serían menos caricaturizables que los de regímenes autoritarios por su carácter más afable y un discurso basado en la cercanía que enmascararía su poder real (Sierra Infante 2011). La burla de la clase política se ejemplificó en mensajes que evidenciaron la degradación de la clase política como "¿Dónde está la izquierda? Al fondo a la derecha", o en readaptaciones del espacio público como la que se produjo durante la acampada en la plaza de Jacinto Benavente, próxima a Sol, donde en una popular estatua de un barrendero se colocaron junto a la escoba y el recogedor de la figura, papeles con nombres de políticos, banqueros y líderes eclesiásticos (entre ellos ZP, Mohammed IV, Revilla, Botín, Aguirre, Rajoy, Obama, Rouco Varela ${ }^{10}$ ). Esta crítica no se habría quedado únicamente en la clase política/empresarial, sino que criticó a la democracia como sistema político, hasta el momento pilar intocable,

10 José Luis Rodríguez Zapatero (ZP), presidente del gobierno de España en ese momento (legislatura entre 2004 y diciembre de 2011). Mohammed IV: Monarca de Marruecos desde 1999 hasta la actualidad. Revilla: presidente del gobierno de Cantabria y economista. Botín, ex presidente del Banco Santander. Esperanza Aguirre, presidenta de la Comunidad de Madrid durante el 15 M y ex ministra de Educación. Rajoy: Actual presidente del gobierno de España desde diciembre de 2011, ex vicepresidente del gobierno y ex ministro. Obama: ex presidente de los EEUU. Rouco Varela: ex cardenal, obispo y arzobispo. 
Ma Isabel Casado, El Humor deslde las Ciencias Sociales. El humor como herramienta de resistencia en movimientos sociales. El caso del 15M., perifèria 22(1), junio 2017

revistes.uab.cat/periferia

con frases como: "Declaramos ilegal la democracia actual", "Me gustas cuando votas porque estás como ausente", o "El pueblo declara ilegal a la democracia actual" (atendiendo a la decisión de la Junta Electoral de prohibir en un primer momento las protestas).

El juego intelectual también puede ser una herramienta colectiva, la denuncia social del 15M utilizó la estética y el ingenio para dotar de fuerza a los mensajes. Mensajes de las pancartas, tales como: "Me sobra mes al final de sueldo", "Deposite su voto aquí" (señalando un retrete), "Se alquila esclavo económico", o la reinterpretación de frases celebres como "Pienso, luego insisto", son ejemplos de cómo el 15M fue capaz de hacer una radiografía de la situación y de exponer lo que reclamaba expresándolo de forma ingeniosa.

El 15M utilizó el humor como forma de mostrar su posesión de capital cultural, es decir, que aunque la juventud, como denunció el movimiento, no tuviese capital económico o posibilidades de futuro en el país, se presenta como la generación mejor preparada, y por tanto, poseyente de un capital cultural suficiente para hacer un uso del lenguaje y del humor creativo, innovador y coherente con las reivindicaciones del movimiento. Esta reflexividad también habría sido una muestra de la superioridad intelectual y política de la ciudadanía con respecto a los políticos y banqueros: "El ministro que firma tu oposición tiene menos formación que tú"; "Mi motivo de indignación, nos educan para no pensar"; "Además de enseñar, enseña a criticar lo que has enseñado"; "No más insultos a mi inteligencia". Pero también una superioridad quizás incluso moral, no olvidemos que en el 15M se realizaron multitud de alusiones a "autoridades morales" como John Lennon, B. Shaw y Gandhi. A través de una lógica original que denunció la desgracia colectiva sin recurrir a la pena, sino que se empoderó a través de la lógica creativa, como por ejemplo la de este mensaje; "No podemos apretarnos el cinturón y bajarnos los pantalones al mismo tiempo".

\section{Conclusiones}

Este trabajo ha pretendido mostrar cómo los recursos ingeniosos, cómicos y originales pueden poner en cuestión el sentido común y un panorama político 
Ma Isabel Casado, El Humor deslde las Ciencias Sociales. El humor como herramienta de resistencia en movimientos sociales. El caso del 15M., perifèria 22(1), junio 2017

revistes.uab.cat/periferia

caracterizado por una presencia de la ciudadanía muy recortada. El humor ha sido considerado como algo propio de los momentos lúdicos, de los espectáculos artísticos, o como reflejo de la personalidad individual, sin embargo, es un proceso muy amplio que se compone de diferentes ámbitos como el emocional, el cognitivo y el socio-estructural. Sería importante resaltar la importancia y relevancia de interpretar socialmente las emociones, y no sólo en términos estructurales e individuales.

El análisis del humor como emoción colectiva en el 15M habría sido una forma estratégica de comunicación y acción, y además una forma de sentir lo denunciado. El humor en el 15M permitió relacionar ámbitos de experiencia cotidiana aislados de una forma creativa, algo que permitió potenciar voces ciudadanas hasta el momento desconectadas entre sí. La creatividad en los movimientos sociales sería un metáfora en sí misma de deconstrucción de la realidad, una visibilidad de que otras formas de organización y relación podrían ser lícitas, resignificando espacios, conceptos, pero también formas de sentir lo político. Centrarse en el aspecto emocional y creativo de los movimientos sociales permite ver algunos procesos para desindividualizar ciertos relatos e historias cotidianas "indignas", sin caer en la compasión y la culpabilidad individual.

\section{Bibliografía}

Abril, G. (1991). Comicidad. Terminología científico- social. Aproximación crítica. España: Anthropos.

Apte, M. (1985). Humor and laughter: An anthropological approach. Cornell University Press.

Bajtin, M. (2003). La cultura popular en la Edad Media y en el Renacimiento. Madrid: Alianza Editorial.

Berger, P. (1999). La risa redentora; La dimensión cómica de la experiencia humana. Barcelona: Kairos.

Bergson, H. (2004). La risa. México: Porrua. 
Ma Isabel Casado, El Humor deslde las Ciencias Sociales. El humor como herramienta de resistencia en movimientos sociales. El caso del 15M., perifèria 22(1), junio 2017

revistes.uab.cat/periferia

Bourdieu, P. (2008). ¿Qué significa hablar?. Barcelona: Akal.

Bruner, M.L. 2005. Carnivalesque Protest and the Humorless State. Text and Performance Quarterly, 25, 136-155.

Ballesteros, L., Casado, I., Godoy, C., \& Sánchez, M. (2016). La representación visual de los "indignados". Aproximación a un análisis visual sobre la caracterización de los participantes del Movimiento 15-M. Nómadas. Revista Crítica de Ciencias Sociales y Jurídicas, 47 (1), 5- 24.

Douglas, M. (1978). Jokes. Implicts meanings; essays in anthropology. The Sociological Quarterl, 19 (2), 355-368.

Diz, Carlos. (2013). Políticas del cuerpo y heteropatías del 15M. Revista de Antropología experimental. Monográfico; etnografías de la indignación, 89111.

Driessen, H. (1999). Humor, risa y trabajo de campo: apuntes desde la antropología. Una historia cultural del humor. Madrid: Sequitur.

Fernández de la Rota, A. (2013). El acontecimiento democrático. Humor; estrategia y estética de la indignación. Revista de Antropología experimiental. Monográfico; etnografías de la indignación, 1- 21.

Ferrer, S., \& Roca, J. (1977). Humor político en la España contemporánea. Madrid: Editorial Cambio.

Freud, S. (2000). El chiste y su relación con el inconsciente. España: Alianza.

Hart, M. (2007). Humour and Social Protest: An Introduction. International Review of Social History, 52, 1-20.

Hiller, H. (1983). Humor and Hostility: A Neglected Aspect of Social Movement. Analysis. Qualitative Sociology, 6, 255-265.

Koestler, A. (1964). The Act of Creation. New York: Penguin Books.

Illouz, E. (2007). Intimidades Congeladas. Las emociones en el capitalismo. Buenos Aires: Katz Editores. 
Ma Isabel Casado, El Humor deslde las Ciencias Sociales. El humor como herramienta de resistencia en movimientos sociales. El caso del 15M., perifèria 22(1), junio 2017

revistes.uab.cat/periferia

Infante C. (2008). Poder, tensión y caricatura. Una aproximación a la teoría del humor. Dialogía: revista de lingüística, literatura y cultura, 3, 245-272.

Jauregui, E. (2008). Universalidad y Variabilidad Cultural de la risa y el humor. AIBR: Revista de Antropología Iberoamericana, 3(1), 46-63.

Lakoff, G., \& Johnson, M. (1995). Metáforas de la vida cotidiana. Madrid, España: Cátedra.

LeBreton, D. (2012). Por una antropología de las emociones. Revista Latinoamericana de Estudios sobre Cuerpos, Emociones y Sociedad, 10, $69 \square 79$.

Lipovetsky, G. (1986). La era del vacío. Ensayos sobre el individualismo contemporáneo. Barcelona: Anagrama.

López, S. (2008). Humor y poder. Una afinidad comunicativa en el proceso social. AIBR. 3 (1), 64-94.

Martin, R. (2008). Psicología del humor: un enfoque integrador. Madrid, España: Orion ediciones.

Mendiburo, A., \& Páez, D. (2011). Humor y cultura. Correlaciones entre estilos de humor y dimensiones culturales en 14 países. Boletín de Psicología, 102. 89105.

Ramírez, E. (2001). Antropología compleja de las emociones humanas. ISEGORÍA, $25,177-200$.

Romanos, E. (2013). The estrategic of humor in the spanish indignados/ 15M movement. 20th International Conference of Europeanists, Amsterdam, 25-27 June 2013.

Romero, A. (2008). La producción especializada del discurso humorístico en un entorno cultural postmoderno. Reis. 109 (05), 75-125.

Sierra, S. (2012). Humor y critica social en la red entorno del 15M. Revista 
Ma Isabel Casado, El Humor des/de las Ciencias Sociales. El humor como herramienta de resistencia en movimientos sociales. El caso del 15M., perifèria 22(1), junio 2017

revistes.uab.cat/periferia

Discurso y Sociedad. Vol. 6(3), 611-635.

Scott, J. (2003). Los dominados y el arte de la resistencia. Mexico: Ediciones Era.

Ibarra, P., \& Tejerina, B. (1998). Los Movimientos sociales. Transformaciones políticas y cambio cultural. Madrid: Trotta.

Vivero, MD. (2001). Humor y subversión de la Doxa. El humor del 15M contra el neo-caca-pipi-talismo. Viento sur: Por una izquierda alternativa, 118, 107-116. 